\title{
Parasitic isopod Anilocra apogonae, a drag for the cardinal fish Cheilodipterus quinquelineatus
}

\author{
Sara Östlund-Nilsson ${ }^{1,4, *}$, Lynda Curtis ${ }^{2}$, Göran E. Nilsson ${ }^{3}$, Alexandra S. Grutter ${ }^{2}$ \\ ${ }^{1}$ Vision, Touch and Hearing Research Centre (VTHRC), School of Biomedical Sciences, and ${ }^{2}$ Department of Zoology \\ and Entomology, University of Queensland Brisbane, Queensland 4072, Australia \\ ${ }^{3}$ Physiology Programme, Department of Molecular Biosciences, University of Oslo, PO Box 1041, 0316 Oslo, Norway \\ ${ }^{4}$ Present address: Department of Biology, University of Oslo, PO Box 1066, 0316 Oslo, Norway
}

\begin{abstract}
Cymothoid isopods Anilocra apogonae are regular ectoparasites of the cardinal fish Cheilodipterus quinquelineatus on the Great Barrier Reef. To determine whether this large isopod, attached to the head of the fish, affects the physiology and behaviour of its host, we conducted morphological measurements to obtain a condition index and several laboratory experiments on fish with and without isopods. The condition index did not vary between parasitised and non-parasitised wild fish. However, we found that parasitised fish lost more weight than unparasitised fish when fed a low food ration. Parasitised fish also had a higher rate of oxygen consumption than non-parasitised fish. When maintaining body posture in calm water, parasitised fish had an elevated pectoral fin beat frequency, probably because the isopod attaches asymmetrically, causing an asymmetrical weight balance for which the fish needs to compensate. Moreover, the sustained aerobic swimming speed as well as the swimming endurance at high water speeds were reduced in parasitised fish, possibly because of the drag from the parasite. The results suggest that parasites can have significant effects on fish even if this is not revealed by their body condition index in the wild. The metabolic effects found imply that parasitised fish may have to spend more time foraging to compensate for their higher metabolism. This could expose them to a higher risk of being eaten, a situation made worse by an impaired swimming ability that may reduce their capacity to escape a predator.
\end{abstract}

KEY WORDS: Parasite $\cdot$ Isopod $\cdot$ Apogonidae $\cdot$ Cardinal fish $\cdot$ Condition index - Resale or republication not permitted without written consent of the publisher

\section{INTRODUCTION}

Members of the isopod family Cymothoidae are among the largest parasites of fishes and are highly host specific (Brusca 1981). Adult cymothoids are usually ectoparasitic on fish, being attached to the skin, gills or oral cavity of their hosts, whereas their juveniles are often free living (Bunkley-Williams \& Williams 1998). Like most isopods, cymothoids are considered to feed principally on blood, but they may consume the mucus, epithelium and subcutaneous tissues of their host (Bunkley-Williams \& Williams 1998). The lifespan of isopods appears to vary from species to species, with most living for 1 to 2 yr (Brusca 1981), while others may live for over $9 \mathrm{yr}$ on the host fish (Maxwell 1982).
In some field studies, fish parasitised with isopods have been found to suffer from reduced condition index and growth (Krykhtin 1951, Kroger \& Guthrie 1972, Sadzikowski \& Wallace 1974, Lanzing \& O'Connor 1975, Romestand \& Trilles 1979, Adlard \& Lester 1994), impaired reproduction and a reduced lifespan (Adlard \& Lester 1994). Several studies have found no harmful effects on the host fish (Weinstein \& Heck 1977, Maxwell 1982, Chang 1999). However, such an apparent lack of effect on the host condition index from the association with the isopod could be explained by the host compensating for a higher rate of energy loss by feeding more than non-parasitised individuals.

At Heron Island, on the Great Barrier Reef, Adlard \& Lester (1994) showed that the cymothoid isopod 


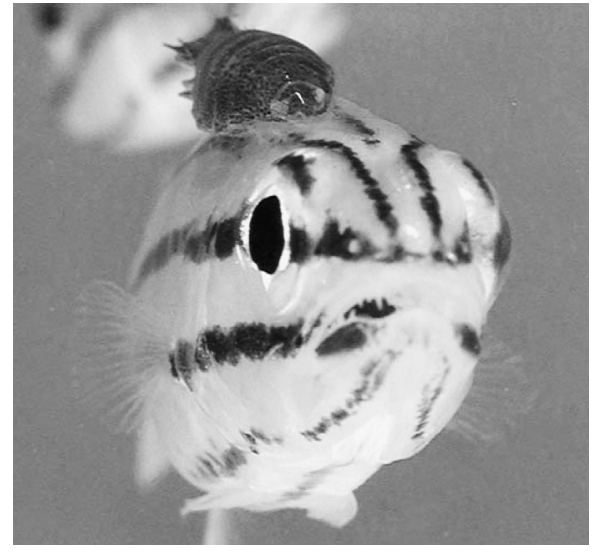

Fig. 1. The host fish Cheilodipterus quinquelineatus and its isopod Anilocra apogonae (photo: G. E. Nilsson)

Anilocra pomacentri depressed the growth, reproduction and survivorship of its host, the damsel fish Chromis nitida. Other fishes also carry similar parasites (Brusca 1981), yet little is known of their effect on their host. In particular, no studies have been done on their effect on host metabolism or swimming performance.

Cardinal fishes (family Apogonidae) are abundant members of tropical and temperate reef fish communities. They are also known to be very site-specific (Marnane 2000). At Lizard Island (Great Barrier Reef), the 5-lined cardinal fish Cheilodipterus quinquelineatus lives sympatrically with several other cardinal fish species among the framework of branching corals, under ledges or in caves. This species is frequently parasitised with the cymothoid isopod Anilocra apogonae (Fig. 1), a strikingly large parasite in the population we studied, its length being about a quarter that of its host. The large size of this parasite relative to the size of the fish raises the question of what affect it has on its host.

To determine the effect of the isopod Anilocra apogonae on the condition of 5-lined cardinal fish, we measured the condition index of wild fish. To examine the effect on host metabolism and behaviour, we tested in the laboratory whether (1) parasitised fish required a higher nutritious input compared to non-parasitised fish, if (2) the isopod affected the metabolism of the host, measured as oxygen consumption, and (3) whether the isopod affected the swimming performance of the fish.

\section{MATERIALS AND METHODS}

The study was conducted during October and November 2000, and continued in February and March 2001 at Lizard Island (14 40' S, 145 28' E), in the northern section of the Great Barrier Reef, Australia. Five-lined cardinal fish Cheilodipterus quinquelineatus with and without an attached Anilocra apogonae were caught while on SCUBA using localised sprays of clove oil to temporarily anaesthetise the fish. The fish were then caught with a small hand net and put into plastic bags, in which they were transported to the laboratory at Lizard Island Research Station (approximately $30 \mathrm{~min}$ ). Fish were placed in aquaria continuously supplied with seawater pumped directly from the ocean. The temperature was 29 to $31^{\circ} \mathrm{C}$.

Body condition index in wild fish. To examine the effect of Anilocra apogonae on the condition index of Cheilodipterus quinquelineatus, parasitised and nonparasitised fish were collected in the field and within $24 \mathrm{~h}$ of capture, fish were killed with an overdose of clove oil solution. For all fish sampled, standard length (mm) (the tip of the snout to the caudal peduncle) and total dry weight $(\mathrm{mg})$ were measured and recorded. Dry weight was measured after drying the fish at $60^{\circ} \mathrm{C}$ for $24 \mathrm{~h}$. In addition, the length (including the uropods) (mm) of the isopods of parasitised C. quinquelineatus was recorded.

Feeding experiment and nutritional status. To determine whether parasitised fish incur a greater reduction in condition factor when fed a low food ration, we conducted a feeding experiment. Parasitised and non-parasitised fish were matched in size (standard length). They were randomly assigned to either a high food ration or to a low food ration. Fish were held individually in opaque aquaria (length $x$ width $\times$ height $=33.7 \times 30.2 \times 27.5 \mathrm{~cm}$ ) divided into 4 equal sections $(\mathrm{L} \times \mathrm{W} \times \mathrm{H}=16.85 \times 15.1 \times 27.5 \mathrm{~cm})$. All fish were supplied with a shelter made from PVC pipe (length = $6 \mathrm{~cm}$, diameter $=5.5 \mathrm{~cm}$ ). Fish in the high-food group were fed twice a day for the duration of the $14 \mathrm{~d}$ experiment. At each feeding, they were fed 3 small pieces of pilchard fish flesh (mean wet weight per piece $=0.200$ $\mathrm{g}$, mean dry weight $=0.032 \mathrm{~g}$ ). Fish in the low-food group were fed the same quantity of food (i.e. in $3 \times$ $0.200 \mathrm{~g}$ in mean weight) but only once on the seventh day of the $14 \mathrm{~d}$ trial. At the conclusion of the experiment, wet weights and standard length measurements of the fish were recorded, while the fish were anaesthetised.

Effect of isopods on fish metabolism. To determine whether an attached isopod was energetically demanding for the fish, we measured the resting oxygen consumption of parasitised $(\mathrm{n}=10)$ and nonparasitised $(\mathrm{n}=8)$ fish in a closed respirometer, as described by Nilsson (1996). The volume of the respirometer chamber was $600 \mathrm{ml}$, and the consumption of $\mathrm{O}_{2}$ was registered with an $\mathrm{O}_{2}$ electrode. Each fish was allowed to acclimate in the respirometer for at least $2 \mathrm{~h}$. The measurement of $\mathrm{O}_{2}$ consumption was 
started by turning off the water supply to the chamber. All fish remained virtually motionless during respirometry, which lasted 50 to $70 \mathrm{~min}$. The experiments were terminated when the water oxygen level fell below $60 \%$ of air saturation.

In addition, the oxygen consumption rates of a subgroup of parasitised fish were measured both before and $48 \mathrm{~h}$ after the removal of the isopod, to quantify the immediate effect of the isopod on the host. We also measured the oxygen consumption rates of isopods $(\mathrm{n}=4)$ that we removed from the fish in order to determine how much the isopod itself contributed to the measured oxygen consumption. The volume of the isopod respirometer was $12 \mathrm{ml}$. The estimated $\mathrm{O}_{2}$ consumption per isopod was subtracted from the total oxygen consumption of each fish with a parasite (taking the parasite weight into account) to obtain the $\mathrm{O}_{2}$ consumption of the fish itself.

In the calculations where parasitised and non-parasitised fish were compared, the oxygen consumption of the isopod was subtracted from the parasitised fish data.

Effect of isopods on fish swimming performance. A swimming chamber was constructed essentially as described by Stobutzki \& Bellwood (1994) and consisted of a $200 \mathrm{~mm}$ long Perspex tube (inner diameter = $52 \mathrm{~mm}$ ). The water was fed into the chamber using a submersible pump (Davey Sump Pump DC10A-2) placed in a $300 \mathrm{l}$ reservoir below the chamber. The reservoir was continuously supplied with seawater at $30 \pm 1^{\circ} \mathrm{C}$. Maximum water flow was $1200 \mathrm{ml} \mathrm{s}^{-1}$, which corresponded to a linear speed of $565 \mathrm{~mm} \mathrm{~s}^{-1}$. A gate valve regulated the speed, and flow rates were calibrated to the angle of the valve. The water was forced through a number of densely packed plastic drinking straws (diameter $=5 \mathrm{~mm}$, length $=45 \mathrm{~mm}$ ) to create a laminar flow in the chamber. The fish was retained in the chamber by the flow straightener in front of the fish and by a plastic mesh $(2.5 \mathrm{~mm}$ mesh size) placed $20 \mathrm{~cm}$ downstream from the flow straightener. The water speed was determined by measuring the volume of water leaving the chamber per unit of time divided by the cross sectional area of the chamber. A single fish was placed in the chamber, the water velocity was set to $25 \mathrm{~mm} \mathrm{~s}^{-1}$ and the fish was allowed to acclimate for $10 \mathrm{~min}$. Like the other cardinal fishes, this species displays a labriform swimming mode (pectoral fin swimming), and therefore uses its pectoral fins for sustained aerobic propulsion, only utilising the caudal fin for very rapid anaerobic swimming bouts (Evans 1997).

Two measures of swimming performance were taken. To measure the maximum sustainable swimming speed, the water velocity was slowly increased until the first bouts of caudal fin beating occurred, then the water speed was lowered until no caudal fin beating occurred, and the water flow at this point was measured. This was considered to be a fully aerobic swimming mode, which was also confirmed in an initial experiment on 4 fish which showed that they were able to maintain this speed for at least $4 \mathrm{~h}$, during which time no caudal fin beating occurred. The water flow was then decreased to $25 \mathrm{~mm} \mathrm{~s}^{-1}$ and fish were allowed to rest for $15 \mathrm{~min}$. The time to fatigue (in seconds) was then measured for the maximum water speed of the swimming apparatus $\left(565 \mathrm{~mm} \mathrm{~s}^{-1}\right)$, which in this case corresponded to 7.4 to 10.3 standard body lengths $\mathrm{s}^{-1}$, since the length of the fish varied between 55 and $76 \mathrm{~mm}$. This water speed was approximately 1.5 to 2.7 times faster than the maximum sustained swimming speed, and forced the fish to continuously use their caudal fin. The fish was considered exhausted when it came to rest against the rear plastic mesh in the chamber, at which point the experiment was terminated.

Effect of isopods on pectoral fin beat frequency. We investigated whether an attached Anilocra apogonae affected the pectoral fin beat frequency of the resting host. Cheilodipterus quinquelineatus beat continuously with their pectoral fins also at rest, probably to maintain their body posture. C. quinquelineatus are commonly seen standing in the water column with their head facing the corals. All individuals seem to have a specific position in the coral and this behaviour makes them very difficult to spot at a distance.

Parasitised and non-parasitised $(\mathrm{n}=28)$ Cheilodipterus quinquelineatus were collected from the field. Each fish was placed in a separate aquarium $(\mathrm{L} \times \mathrm{W} \times$ $\mathrm{H}=20 \times 30.5 \times 20 \mathrm{~cm}$ ) and allowed to acclimate for $24 \mathrm{~h}$. Trials were conducted each day between 14:00 and $15: 00 \mathrm{~h}$ to avoid possible variability caused by diurnal changes in activity levels of the fish. The water flow was turned off and the air stone removed $10 \mathrm{~min}$ prior to the beginning of each trial to eliminate water currents. The pectoral fin beat of each fish was counted over a $5 \mathrm{~min}$ period.

To determine whether the removal of the isopod resulted in a change in pectoral fanning, a second group of parasitised $(n=5)$ and non-parasitised $(n=5)$ Cheilodipterus quinquelineatus were subjected to this same procedure both before and $24 \mathrm{~h}$ after the removal of the isopod from the fish. The isopods were generally removed with a pair of forceps after lightly anaesthetising the parasitised fish in clove oil.

Statistical procedure. Data are given as means $\pm \mathrm{SD}$ and were checked for normality. Parametric and nonparametric tests were chosen accordingly. In some figures, percentage values are displayed, but in the statistical calculations, percentages/proportions were arcsine-square-root-transformed. Fish condition index was estimated by the residuals from the correlation 
between wet weight and standard length. We used Fulton's condition index (weight/length ${ }^{3}$ ) since this is a common method of measuring condition in fish.

\section{RESULTS}

\section{Body condition index in wild fish}

The isopods were always found attached just posterior and dorsal to the eye of the host fish, on either side of the midline (never centrally). Host and isopod standard length were positively correlated $(n=24, r=0.49$, $\mathrm{p}<0.02)$. The average host parasite length ratio was 1:0.26 mm (54.4 $\pm 8.45 \mathrm{~mm}, \mathrm{n}=24$ and isopod length $14.3 \pm 1.69 \mathrm{~mm}, \mathrm{n}=24$, respectively). There was no difference in condition index, between parasitised ( $\mathrm{n}=$ 23, Fulton's condition index \pm SD: $5.04 \times 10^{6} \pm 5.06 \times$ $\left.10^{7}\right)$ and non-parasitised $\left(n=23,5.13 \times 10^{6} \pm 8.93 \times 10^{7}\right)$ Cheilodipterus quinquelinatus, measured directly after being caught (unpaired $t$-test, $\mathrm{t}=0.38, \mathrm{p}=0.70$ ).
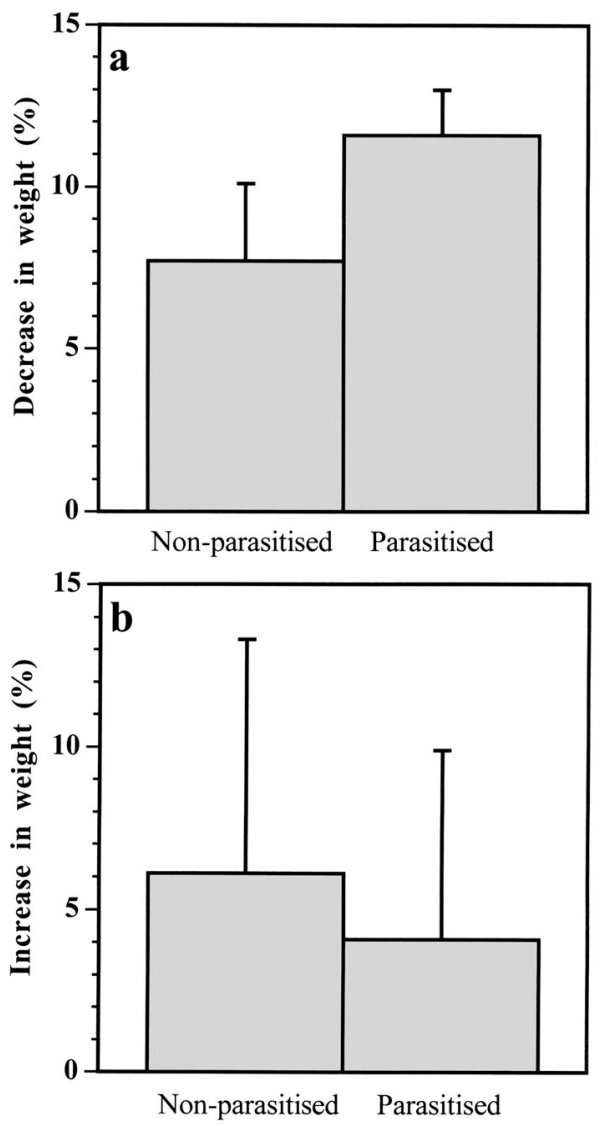

Fig. 2. Cheilodipterus quinquelineatus. Percent of weight change over $14 \mathrm{~d}$ for the cardinal fish C. quinquelineatus with and without the parasitic isopod Anilocra apogonae exposed to either (a) a low-food treatment or (b) a high-food treatment

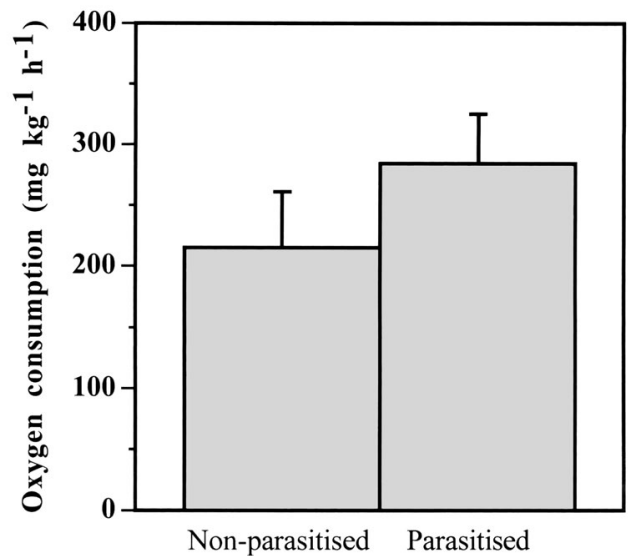

Fig. 3. Cheilodipterus quinquelineatus. Resting rate of oxygen consumption for cardinal fish $C$. quinquelineatus, with and without the parasitic isopod Anilocra apogonae

\section{Feeding experiment and nutritional status}

In the low-food treatment, we found that the parasitised fish $(\mathrm{n}=13)$ lost significantly more weight (calculated as the weight difference between the start and end of the experiment and then divided by the start weight) compared to the non-parasitised fishes $(\mathrm{n}=13)$ (unpaired $t$-test, $t=5.1, \mathrm{p}<0.0001$, Fig. 2a). In the high-food treatment, both parasitised and nonparasitised fishes gained weight (both $\mathrm{n}=11$ ), but there was no difference between the parasitised and non-parasitised group in weight change during the trial (unpaired $t$-test, $t=0.51, \mathrm{p}=0.613$, Fig. $2 \mathrm{~b}$ ).

\section{Effect of isopods on fish metabolism}

The resting rate of oxygen consumption for parasitised Cheilodipterus quinquelineatus ( $\mathrm{n}=10$, weight $=5.51 \pm 0.82 \mathrm{~g}$ ) was $25 \%$ higher than that of non-parasitised individuals $(\mathrm{n}=8$; weight $=5.86 \pm$ 0.96 g; Mann-Whitney $U$-test, $U=70, \mathrm{p}=0.008$, Fig. 3).

The removal of the isopod from another group of fish resulted in a $23 \%$ fall in their oxygen consumption, from $292 \pm 41.8$ to $224 \pm 26.9 \mathrm{mg} \mathrm{O}_{2} \mathrm{~kg}^{-1} \mathrm{~h}^{-1}$ (measured after $24 \mathrm{~h}, \mathrm{n}=7$, weight $=4.84 \pm 1.05 \mathrm{~g}$; Wilcoxon signed rank test; $Z=2.4, \mathrm{p}=0.018$ ). When the oxygen consumption rate of these fish that had had their isopods removed was compared to that of the above non-parasitised fish (from Fig. 3), the difference was not significant (Mann-Whitney $U$-test, $U=25.0, \mathrm{p}=$ 0.73).

Interestingly, the mass-specific $\mathrm{O}_{2}$ consumption of the isopod parasite $\left(294 \pm 95.2 \mathrm{mg} \mathrm{O}_{2} \mathrm{~kg}^{-1} \mathrm{~h}^{-1}, \mathrm{n}=4\right.$, weight of isopod $=103 \pm 8 \mathrm{mg}$ ) was similar to that of its host. 


\section{Effect of isopods on fish swimming performance}

The maximum sustainable (aerobic) swimming speed of the isopod-parasitised fish $(n=12)$ was approximately $13 \%$ lower than that of non-parasitised fish ( $\mathrm{n}=15$; unpaired $t$-test: $t=2.66, \mathrm{p}=0.014$, Fig. $4 \mathrm{a})$. At the maximal speed that could be produced by the swim tunnel, the parasitised fish also swam for a much shorter time before reaching fatigue $(n=22)$ compared to the non-parasitised individuals ( $\mathrm{n}=20$; unpaired $t$-test: $t=2.05, \mathrm{p}=0.047$, Fig. $4 \mathrm{~b}$ ).

The measures of swimming performance did not correlate with fish standard length for parasitised and non-parasitised fish (maximum sustained swimming speed: parasitised, $\mathrm{n}=13, \mathrm{r}=0.23, \mathrm{p}=0.46$; nonparasitised, $\mathrm{n}=15, \mathrm{r}=0.23, \mathrm{p}=0.43$; time to fatigue: parasitised, $\mathrm{n}=11, \mathrm{r}=0.24, \mathrm{p}=47$; non-parasitised, $\mathrm{n}=$ $16, r=0.30, p=0.26$ ). Thus, fish size did not have to be taken into account.

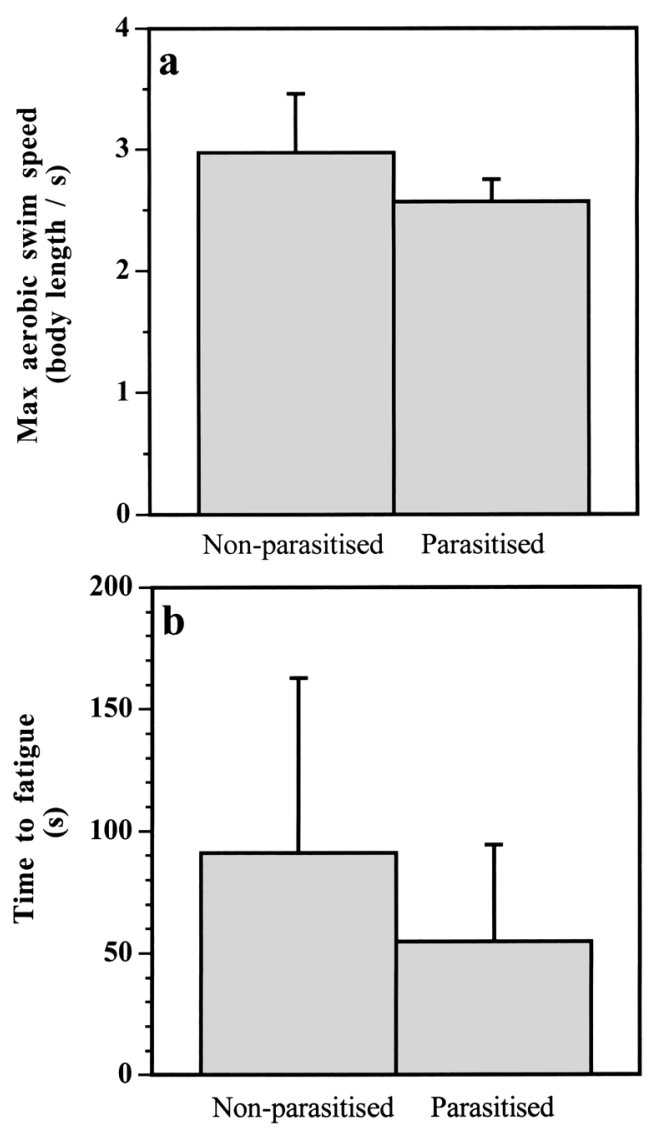

Fig. 4. Cheilodipterus quinquelineatus. Swimming performance of the cardinal fish C. quinquelineatus with and without the parasitic isopod Anilocra apogonae measured as (a) the maximum sustained (aerobic) swimming speed and (b) the time to fatigue

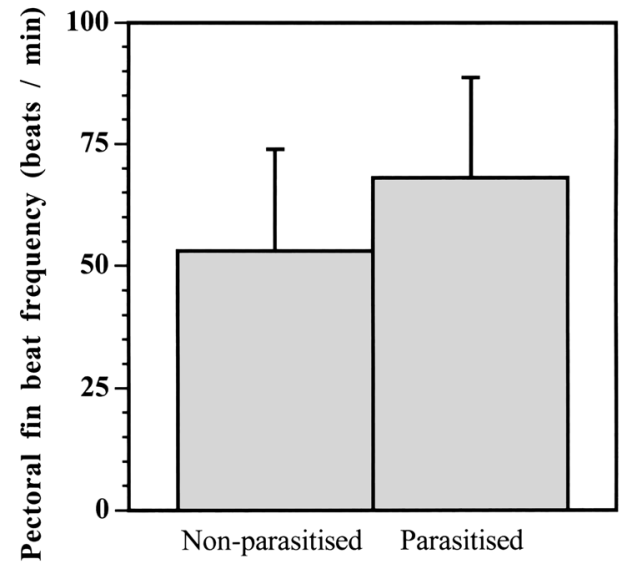

Fig. 5. Cheilodipterus quinquelineatus. Pectoral fin beat frequency of the cardinal fish C. quinquelineatus with and without the parasitic isopod Anilocra apogonae, while standing still in the water column

\section{Effect of isopods on pectoral fin beat frequency}

When remaining still, the pectoral fin beat frequency of parasitised $(\mathrm{n}=29)$ Cheilodipterus quinquelineatus was approximately $23 \%$ higher than that of nonparasitised fish $(\mathrm{n}=28)$ (unpaired $t$-test; $t=2.7, \mathrm{p}=$ 0.008, Fig. 5). The fin beats, after the removal of the isopod from a second group of parasitised fish, decreased but not significantly (parasitised fish before removal of isopod: $n=12$, mean \pm SD: $60.1 \pm 12.6$ fin beats $\mathrm{min}^{-1}$; same individuals after removal of the isopod: $\mathrm{n}=12$, mean $\pm \mathrm{SE}: 56.5 \pm 17.3$ fin beats $\mathrm{min}^{-1}$, paired $t$-test; $t=0.7, \mathrm{p}=0.49$ ). However, the fin beat frequency of these previously parasitised fish $(\mathrm{n}=12$, mean $\pm \mathrm{SD}: 56.5 \pm 17.4$ fin beats $\mathrm{min}^{-1}$ ) was not significantly different from that of naturally nonparasitised fish $\left(\mathrm{n}=28\right.$, mean \pm SD: $53.1 \pm 20.8$ fin beats $\min ^{-1}$; unpaired $t$-test; $t=0.5, \mathrm{p}=0.62$ ), indicating that the removal of Anilocra apogonae resulted in recovery with regard to pectoral fanning.

There were no differences in the standard length between the parasitised group $(54.4 \pm 9.0 \mathrm{~mm}, \mathrm{n}=22)$ and the non-parasitised group $(56.3 \pm 8.8 \mathrm{~mm}, \mathrm{n}=18)$ of fish used in the experiment (unpaired $t$-test, $t=0.68$, $\mathrm{p}=0.51)$.

\section{DISCUSSION}

We found that the condition index of wild-caught Cheilodipterus quinquelineats did not differ between fish with and without the parasitic isopod Anilocra apogonae. Our laboratory experiments, however, show that this does not necessarily mean that these parasites have no effect on their host. The results of our feeding 
experiment suggest that this apparent lack of effect in the wild might be due to an ability of the fish to compensate for the energetic drain of the parasites by increasing food intake. The feeding experiment showed that the parasitised fish lost $35 \%$ more weight than non-parasitised fish when held on a low-food regimen. By contrast, the fish receiving large rations of food, all gained a similar amount of weight regardless of being parasitised or not. Thus, A. apogonae only had a significant effect on fish weight when food supply was limited. This clearly indicates that the isopods do affect the energy balance of the host, but that this can be compensated for with high levels of food intake; thus, it is possible that fish surviving the parasite association may be high quality individuals that normally would have had a higher condition index than the population average.

However, if parasitised fish have to increase their foraging efforts, this could have drastic consequences for their survival, as foraging is often associated with the risk of being eaten. Previous studies have shown that fish which are under energetic stress due to parasites have a greater need for energy and are, therefore, more willing to compromise safety from predation for foraging gains (Giles 1987, Godin \& Sproul 1987).

The fact that the isopod infection increased the demand for energy was corroborated by our measurements of resting oxygen consumption, suggesting that the resting metabolic rate was $25 \%$ higher in parasitised fish. Sticklebacks bloated by Schistocephalus cestodes, have also been found to have an elevated oxygen consumption (Lester 1970). This was attributed to the energy involved in overcoming the extra hydrodynamic resistance encountered by the bloated fish. The crabs Hemigrapsus crenulatus, when parasitised by the acanthocephalan parasite Profilicollis antarcticus, also have a higher metabolic rate (Haye \& Ojeda 1998). Several studies have indicated that parasitised fish have greater energy requirements as a result of the parasite's use of a portion of their assimilated energy stores (Walkey \& Meakins 1970, Giles 1987, Godin \& Sproul 1987, Lozano 1991).

In our population, however, we speculate that this may not be the main cost, especially since brooding isopods do not feed and Anilocra are brooding most of the time. Unfortunately, we could not control for this in our study. In our population, no fish were ever observed with more than 1 isopod and the body mass of the isopod was only about $1 / 60$ of that of the fish. Since the isopod had a mass specific rate of metabolism that was virtually identical to that of the host, the relationship of host to parasite metabolic rate should therefore be 1:60; thus, the metabolic effect from a possible non-brooding and feeding isopod would probably have been negligible.
Another and probably more noteworthy factor that could account for a substantial part of the energetic cost of being parasitised could be the hydrodynamic consequences of such a relatively bulky and asymmetrically attached parasite. The parasite was always situated off-centre, on either side of the midline. Our measurements of pectoral fin beat frequency in resting fish showed that parasitised fish were beating their pectoral fins at a rate $23 \%$ higher than non-parasitised individuals. Pectoral fins are used to maintain balance in fish (Jobling 1995). Most likely, the increased activity in pectoral fin beats was related to a need for increased fanning to maintain the equilibrium of the body posture when burdened with an asymmetrically placed parasite. During the day, Cheilodipterus quinquelineatus primarily occupied territories within the coral, where they remained relatively stationary rather than constantly swimming; thus, much of the energy devoted to fin movements is possibly used for posture control rather than sustained movement in this species.

Non-parasitised adult Cheilodipterus quinquelineatus reacted violently if an Anilocra apogonae larva was placed on the head; parasitised fish did not exhibit erratic behaviour. This may be because cymothoid isopods attach to juvenile fish and become permanent parasites (Menzies et al. 1955, Weinstein \& Heck 1977, Maxwell 1982, Adlard 1989), and parasitised C. quinquelineatus may, over time, become behaviourally 'acclimated' to the presence of the isopod (Williams et al. 1982). This suggests that the increase in pectoral fin beats of parasitised fish is less likely to be due to a stress response and more likely to be caused by the off-centred position of the parasite.

We also found that the maximum sustainable (aerobic) swimming speed, and the swimming endurance at a very high (anaerobic) speed, were both lower in parasitised Cheilodipterus quinquelineatus. This implies that the impaired swimming performance was related to the increased hydrodynamic drag caused by the parasite. There is a striking parallel in studies showing that external tagging devices on fish reduce swimming performance by acting as a hydrodynamic drag burden (Lewis \& Muntz 1984, Mellas \& Hayes 1985, Serafy et al. 1995, Adams et al. 1998) or the impact of sea lice infection on the swimming performance of Atlantic salmon (Wagner et al. 2003).

Slower sustained swimming speeds and more rapid times to fatigue may have a number of implications for fish. As Cheilodipterus quinquelineatus travel to feeding grounds at night (Marnane 2000), their ability to migrate could be affected due to a reduction in mobility and endurance (Sprengel \& Luchtenberg 1991) caused by the parasite.

Their ability to swim against water currents may also be compromised by the isopod Anilocra apogonae. 
At Lizard Island, water currents can reach 100 to $300 \mathrm{~mm} \mathrm{~s}^{-1}$ (Frith et al. 1986), which for Cheilodipterus quinquelineatus correspond to 1.2 to 6 body lengths $\mathrm{s}^{-1}$. In other words, the fish have to swim actively against the high and low tide currents to avoid drifting away from their home territory. This could potentially affect the range of habitats that parasitised fish can choose from if they need to avoid currents. Perhaps parasitised individuals may live closer to foraging grounds to minimise the cost of travel from their resting place. Moreover, a decrease in rapid anaerobic swimming bursts may reduce an individual's ability to avoid and escape predation (Sprengel \& Luchtenberg 1991, Coleman 1993, Serafy et al. 1995, Adams et al. 1998), and to capture live food (Coleman 1993, Serafy et al. 1995). This may be especially detrimental for parasitised $C$. quinquelineatus as they may have to spend more time foraging for food due to the energetic stress caused by the association of the isopod, as shown by the feeding experiments. In contrast, parasitised individuals might have a reduced conspicuousness in the presence of a predator due to behavioural changes, as is the case in the grass shrimp Palaemonetes pugio (Bass \& Weis 1999).

Acknowledgements. We thank the staff at Lizard Island Research Station for their generous help. The study was funded by the Research Council of Norway (S.Ö.-N. and G.E.N.), the Vision, Touch, and Hearing Research Center and the School of Life Sciences, University of Queensland (S.Ö.-N., A.S.G.), and the Australian Research Council (A.S.G.). The study was conducted with permits from the Great Barrier Reef Marine Park Authority (G01/298) and Queensland Fisheries (PRMO2356F), and followed the guidelines for animal experimental use of the University of Queensland (VTHRC/086/01/NRC and ZOO/ENT/176/01/H/UQ).

\section{LITERATURE CITED}

Adams NS, Rondorf DW, Evans SD, Kelly JE, Perry RW (1998) Effects of surgically and gastrically implanted radio transmitters on swimming performance and predator avoidance of juvenile chinook salmon (Oncorhynchus tshawytscha). Can J Fish Aquat Sci 55:781-787

Adlard RD (1989) The effects of the parasitic isopod Anilocra pomacentri Bruce (Cymothoidae) on the population dynamics of the reef fish Chromis nitida Whitley (Pomacentridae). PhD thesis, University of Queensland

Adlard RD, Lester RJG (1994) Dynamics of the interaction between the parasitic isopod, Anilocra pomacentri, and the coral reef fish, Chromis nitida. Parasitology 109: 311-324

Bass CS, Weis JS (1999) Behavioral changes in the grass shrimp, Palaemonetes pugio (Holthuis), induced by the parasitic isopod, Probopyrus pandalicola (Packard). J Exp Mar Biol Ecol 241:223-233

Brusca RC (1981) A monograph on the Isopods Cymothoidae (Crustacea) of the eastern Pacific. Zool J Linn Soc 73: 117-199

Bunkley-Williams L, Williams E (1998) Isopods associated with fishes: a synopsis and corrections. J Parasitol 84: 893-896

Chang L (1999) Observations on Catoessa ambassae and other cymothoid isopods parasitic on fish. PhD thesis, University of Queensland

Coleman FC (1993) Morphological and physiological consequences of parasites encysted in the bulbus-arteriosus of an estuarine fish, the sheepshead minnow, Cyprinodon variegatus. J Parasitol 79:247-254

Evans DH (1997) The physiology of fishes. CRC Press, New York

Frith CA, Leis JM, Goldman B (1986) Currents in the Lizard Island region of the Great Barrier Reef lagoon and their relevance to potential movements of larvae. Coral Reefs 5:81-92

Giles N (1987) Predation risk and reduced foraging activity in fish: experiments with parasitized and non-parasitized three-spined sticklebacks, Gasterosteus aculeatus. J Fish Biol 31:37-44

Godin JJ, Sproul CD (1987) Risk taking in parasitized sticklebacks under threat of predation: effects of energetic need and food availability. Can J Zool 66:2360-2367

Haye PA, Ojeda PF (1998) Metabolic and behavioural alterations in the crab Hemigrapsus crenulatus induced by its acanthocephalan parasite Profilicollis antarcticus. J Exp Mar Biol Ecol 228:73-82

Jobling M (1995) Environmental biology of fishes. Chapman \& Hall, London

Kroger RL, Guthrie JF (1972) Incidence of the parasitic isopod Olencira in juvenile menhaden. Copeia 2:370-372

Krykhtin ML (1951) Some notes on the effects of the parasitic isopod Livoneca amurensis on the stocks of Leuciscus waleckii in the Amur. Trans Amursk Ichthyol Exped 11: 1945-1949

Lanzing WJR, O'Connor PF (1975) Infestation of luderick (Girella tricuspidata) populations with parasitic isopods. Aust J Mar Freshw Res 26:355-361

Lester RJG (1970) The influence of Schistocephalus plerocercoids on the respiration of Gasterosteus and a possible resulting effect on the behaviour of the fish. Can J Zool 49:361-366

Lewis AE, Muntz WRA (1984) The effects of external ultrasonic tagging on the swimming performance of rainbow trout, Salmo gairdneri Richardson. J Fish Biol 25:577-585

Lozano GA (1991) Optimal foraging theory: a possible role for parasites. Oikos 60:391-395

Marnane MJ (2000) Site fidelity and homing behaviour in coral reef cardinalfishes. J Fish Biol 57:1590-1600

Maxwell JGH (1982) Infestation of the jack mackeral, Trachurus declivis (Jenyns), with the cymothoid isopod, Ceratothoa imbricatus (Fabricus), in south eastern Australian waters. J Fish Biol 20:341-349

Mellas EJ, Haynes JM (1985) Swimming performance and behaviour of rainbow trout (Salmo gairdneri) and white perch (Morone americana): effects of attaching telemetry transmitters. Can J Fish Aquat Sci 42:488-493

Menzies RJ, Bowman TE, Alverson FG (1955) Studies of the biology of the fish parasite Livoneca convexa Richardson (Crustacea, Isopoda, Cymothoidae). Wasmann J Biol 13: 277-295

Nilsson GE (1996) Brain and body oxygen requirements of Gnathonemus petersii, a fish with an exceptionally large brain. J Exp Biol 199:603-607

Romestand B, Trilles JP (1979) Influence des cymothoadiens Meinertia oestroides, Meinertia parallea et Anilocra physodes (Crustacés, Isopodes; parasites de poissons) sur la croissance des poissons hotes Boops boops et Pagellus 
erythrinus (Sparides). Z Parasitenkd Parasitol Res 59:195-202

Sadzikowski MR, Wallace DC (1974) The incidence of Livoneca ovalis (Say) (Crustacea, Isopoda) and its effects on the growth of white perch, Morone americana (Gmelin), in the Delaware River near Artificial Island. Chesapeake Sci 15:163-165

Serafy JE, Lutz SJ, Capo TR, Ortner PB, Lutz PL (1995) Anchor tags affect swimming performance and growth of juvenile red drum (Sciaenops ocellatus). Mar Freshw Behav Physiol 27:29-35

Sprengel G, Luchtenburg H (1991) Infection by endoparasites reduces maximum sustained speed of European smelt Osmerus eperlanus and European eel Anguilla anguilla. Dis Aquat Org 11:31-35

Stobutzki IC, Bellwood DR (1994) An analysis of the sustained

Editorial responsibility: Charles Birkeland (Contributing Editor), Honolulu, Hawaii, USA swimming abilities of pre- and post-settlement coral reef fishes. J Exp Mar Biol Ecol 175:275-286

Wagner GN, McKinley RS, Bjørn PA, Finstad B (2003) Physiological impact of sea lice on swimming performance of Atlantic salmon. J Fish Biol 62:1000-1009

Walkey M, Meakins RH (1970) An attempt to balance the energy budget of a host-parasite system. J Fish Biol 2: 361-372

Weinstein MP, Heck KL (1977) Biology and host-parasite relationships of Cymothoa excisa (Isopoda, Cymothoidae) with three species of snappers (Lutjanidae) on the Caribbean coast of Panama. Fish Bull 75:875-877

Williams EH, Bunkley-Williams L, Waldner RE, Kimmel JJ (1982) Predisposition of a pomacentrid fish, Chromis multileneauts (Guichenot) to parasitism by a cymoithoid isopod, Anilocra chromis. J Parasitol 68:942-945

Submitted: January 23, 2004; Accepted: October 7, 2004 Proofs received from author(s): January 26, 2005 